\title{
Influence of Storage Times on Bond Strength of Resin Cements to Root Canal
}

\author{
Matheus Cô̂lho Bandéca ${ }^{\mathrm{a}, \mathrm{b} *}$, Amr Shebl Kassem ${ }^{\mathrm{b}, \mathrm{c}}$, Omar El-Mowafy ${ }^{\mathrm{b}}$, Michele Regina Nadalin $^{\mathrm{d}}$, \\ Renato Souza Queiroz, ${ }^{\mathrm{a}}$,Victor Rene Grover Clavijo ${ }^{\mathrm{a}}$,José Roberto Cury Saad ${ }^{\mathrm{a}}$ \\ a Department of Restorative Dentistry, Araraquara School of Dentistry, \\ University of São Paulo State - UNESP \\ 1680 Humaitá St., 14801-903 Araraquara - SP, Brazil \\ ${ }^{\mathrm{b}}$ Department of Restorative Dentistry, Faculty of Dentistry, University of Toronto \\ Toronto, ON M5G 1 G6 \\ ${ }^{\circ}$ Crown and Bridge Department, Faculty of Dentistry, \\ Suez Canal University, Ismailia, Egypt \\ ${ }^{\mathrm{d}}$ University of Ribeirão Preto, 2.201 Costábile Romano Ave, Ribeirão Preto - SP, Brazil
}

Received: April 25, 2009; Revised: January 27, 2010

\begin{abstract}
The resin cements are responsible to retention of the indirect materials decreasing marginal leakage, increasing failure resistance compared with conventional cementation. The cementation within root canal is very hard due unfavorable conditions regarding the application of adhesive techniques caused by inadequate access. Therefore, considering the possibility to decrease steps of cementation, this study was performed to evaluate the bond strength of self-adhesive resin cement (RelyX ${ }^{\mathrm{TM}} \mathrm{U} 100,3 \mathrm{M}$ ESPE) and resin cement combined with self-ecthing adhesive system (Panavia ${ }^{\circledR}$ F 2.0, Kuraray) light-cured with Quartz Tungsten Halogen (QTH) following storage at $37^{\circ} \mathrm{C}$ immediately after light-curing, 24 and 48 hours and 7 days. The root canals were prepared to receive the glass fiber post in the depth of $10 \mathrm{~mm}$, irrigated with $17 \%$ EDTA and $\mathrm{NaOCl}$, rinsed with distilled water and dried using paper points. The roots were perpendicularly sectioned into approximately $1 \mathrm{~mm}$ thick sections, obtaining ninety-six slices $(n=12)$. The slices were trimmed using a cylindrical diamond bur in the proximal surfaces until it touched the post and attached into a device, which were mounted on a strength tester (Bisco) and loaded in tension at a speed of $0.5 \mathrm{~mm} / \mathrm{min}$ until failure occurred at specimens. The analysis of variance (ANOVA) and Tukey's post-hoc tests showed significant statistical differences $(P<.05)$ to all resin cements immediately after light-curing and 24 hours, 48 hours and 7 days. The Panavia ${ }^{\circledR}$ F 2.0 showed higher mean values than RelyX ${ }^{\mathrm{TM}}$ U100 for all storage times, however no different statistically significant was reported $(P>.05)$. The resin cements 24 and 48 hours after light-curing were statistically similar among themselves $(P>.05)$. The both resin cement showed similar bond strength into root canal on different storage times. The highest bond strength values of the resin cements were showed 7 days after curing.
\end{abstract}

Keywords: adhesion, dental polymers, light curing, polymerization

\section{Introduction}

Successful bonding of luting agents to tooth structure is essential for decrease marginal leakage with improved apical seal, increases failure resistance compared with conventional cementation and retention of material bonded of indirect materials ${ }^{1-4}$. Many resin cements are available on the market, which are used frequently for the cementation of the majority of esthetic porcelain, ceramic, indirect composite restorations and non-metallic posts ${ }^{5}$.

The resin cements are polymerized via chemical- or light-curing, and some resin cements use both mechanisms of cure are referred to as "dual-cure" cements". This dual-cure mechanism is effective to control of working time and the possibility of achieving adequate conversion degree and is ideal for situations in which root depth might make it difficult for light to reach the full thickness of the cement layer ${ }^{7}$. They can be found into self-adhesive, combined with self-ecthing or etch-and-rise systems. The self-adhesive resin cement does not require any pretreatment of dentin. The simplification of the technique application with these new materials is simplifying the cementation procedure and operator-sensitive than when using etch-and-rise systems ${ }^{8-12}$.

The process of polymerization occurs by conversion of the carbon double bonds in carbon single bonds that can be measure through conversion degree ${ }^{5}$. The extent to which monomers react to form polymers during the polymerization reaction is affect the physical properties of dental resins ${ }^{13}$.

The cementation within root canal is very difficult due unfavorable conditions regarding the application of adhesive techniques caused by inadequate access and the type of post used ${ }^{14}$.

Nonmetallic posts are made either from a resin matrix reinforced with carbon, glass or quartz fibers or from ceramic materials ${ }^{15}$. With the exception of carbon posts, which showed more favorable esthetics in anterior teeth when restored with all-ceramic crowns due to their 
light-transmitting capacity, in addition to their modulus of elasticity are similar to dentine and resin materials ${ }^{16}$.

Bandéca et al. ${ }^{5}$ evaluated the conversion degree of two dual-cure resin cements following storage at $37{ }^{\circ} \mathrm{C}$ immediately after lightcuring, 24 and 48 hours and 7 days. The results showed the RelyX ${ }^{\mathrm{TM}}$ Unicem (Aplicap ${ }^{\mathrm{TM}}$ ) presented higher values of conversion degree than Panavia ${ }^{\circledR}$ F 2.0 and the results were higher to 7 days after lightcuring than 24 and 48 hours.

Microtensile, push-out and pull-out tests have been used to evaluate the bond strength of luting materials ${ }^{17,18-20}$ that can be luting material-dentine/post interfaces. In push-out test, the bond strength is evaluated by the retention created not only by luting agent but also through micro and macro-retention by surface roughness and frictional fit between two surfaces, respectively ${ }^{15,19}$.

This study was performed to evaluate the bond strength of dualcure resin cement light-cured with Quartz Tungsten Halogen (QTH) following storage at $37{ }^{\circ} \mathrm{C}$ immediately, 24 hours, 48 hours and 7 days after light-curing.

\section{Materials and Methods}

\subsection{Materials used}

Tested materials are listed on Table 1.

\subsection{Specimens' preparation}

The crowns of the teeth were removed at the cement-enamel junction using a low-speed diamond disc (Isomet III; Buehler, Lake Bluff, IL) under constant water-cooling.

The root canals were prepared until $1 \mathrm{~mm}$ from the apex using rotary nickel-titanium instruments (Mity, Loser, Leverkusen, Germany) according to the crown-down technique. The master apical file was 40.06 and the irrigation solution between instrumentation was $2.5 \% \mathrm{NaOCl}$. Prepared root segments were obturated with gutta-percha and an epoxy resin-based canal sealer (AH Plus ${ }^{\circledR}$, Dentsply DeTrey, Konstanz).

The roots were randomly distributed and separated into eight groups reported in Table 2.

\subsection{Post space preparation}

After endodontic therapy, the roots were stored in distillated water at $37{ }^{\circ} \mathrm{C}$ for 48 hours. The post space was prepared with the drills designated for the Exacto ${ }^{\circledR}$ posts in the depth of $10 \mathrm{~mm}$.

\subsection{Bonding procedure}

The luting materials were used of according with manufacturer's instructions. Before application of resin cements, root canals were irrigated with $17 \%$ EDTA and $2.5 \% \mathrm{NaOCl}$, rinsed with distilled water and dried using paper points (Dentsply Maillefer). The Panavia
F 2.0 is self-curing resin cement that is used in combination with the 1-step self-etching ED Primer. Equal amounts of the 2 liquids of ED Primer were mixed and applied into the canal with a microbrush. The reaction time was 60 seconds, and consecutively base and catalyst paste were mixed and applied inside the root canal and around the post surfaces. RelyX U100 is self-adhesive resin cement that does not require any pretreatment of dentine. The base and catalyst paste were mixed and applied to equal Panavia's application. Insertion and light-curing (Optilux 401) through the post followed for 60 seconds. The cervical region of the root was sealed with composite resin TPH Spectrum Compule (Dentsply Caulk, Milford, USA) applied in $2 \mathrm{~mm}$ increment. The materials were light-activated with Optilux 501 (Demetron Kerr, Orange, CA). Before each bonding procedure, the power density of the light-activated was checked with digital radiometer. The mean power density of the light-activated was $500 \pm 10 \mathrm{~mW} \cdot \mathrm{cm}^{-2}$. The specimens were stored in distillated water at $37{ }^{\circ} \mathrm{C}$ until bond strength testing.

\subsection{Cutting procedure}

Specimens were fixed with sticky wax into a device adapted to the cutting machine (Isomet III; Buehler, Lake Bluff, IL) and perpendicularly sectioned into approximately $1 \mathrm{~mm}$ thick sections using a low-speed diamond disc under constant water-cooling, resulting in ninety-six slices $(\mathrm{n}=12)$.

\subsection{Bond strength testing}

Twelve slices from each group were trimmed using a cylindrical diamond bur (\#1090, KGSorensen, Barueri, SP, Brazil) under watercooling in the proximal surfaces until it touched the post.

A digital caliper (Deigimatic Caliper ${ }^{\circledR}$, Mitutoyo $^{\circledR}$, Kawasaki $^{\circledR}$, Japan $^{\circledR}$ ) with $0.01 \mathrm{~mm}$ precision was used to measure the thickness of each slice. The slices were attached into a device (Bisco Inc)

Table 2. Groups performed to this investigation.

\begin{tabular}{ccc}
\hline Group & Resin material & \\
\hline I & Panavia $^{\circledR}$ F 2.0 & Immediately \\
II & & 24 hours \\
III & & 48 hours \\
IV & & 7 days \\
V & RelyX $^{\mathrm{TM}}$ U100 & Immediately \\
VI & & 24 hours \\
VII & & 48 hours \\
VIII & & 7 days \\
\hline
\end{tabular}

Table 1. Dental materials used in this study.

\begin{tabular}{llll}
\hline \multicolumn{1}{c}{ Resin cement } & \multicolumn{1}{c}{ Composition } & \multicolumn{1}{c}{ Manufacturer } \\
\hline Panavia $^{\circledR}$ F 2.0 Base & 10-MDP, 5-NMSA, silica, dimethacrylates, initiator & Kuraray Medical & 00265B \\
Panavia $^{\circledR}$ F 2.0 Catalyst & Barium glass, sodium fluoride, dimethacrylates, BPO & Tokyo, Japan & 00043B \\
Rely $^{\mathrm{TM}}$ U100 (Clicker $^{\mathrm{TM}}$ & Glass powder, silica calcium hydroxide, pigment, substituted & 3M/Espe Seefeld, 315751 \\
Dispenser) Base & pyrimidine, peroxy compound, initiator & Germany \\
RelyX $^{\mathrm{TM}}$ U100 & Methacrylated, phosphoric esters, Dimethacrylates, Acetate, & \\
(Clicker $^{\mathrm{TM}}$ Dispenser) Catalyst & Stabilizers, Self-cure initiators, Light-cure initiators & \\
Exacto $^{\circledR}$ Post & Glass fiber: 87\% volume, Epoxy resin: 13\% volume, Internal & Angelus, \\
& filament: stainless steel. Design post: Cervical diameter, 1.8 & Londrina, Brazil \\
& mm, Middle diameter, 1.8 mm, Apical diameter, 1.1 mm & \\
\hline
\end{tabular}


with cyanoacrylate glue (Zapit; Dental Ventures of America Inc, Corona, Calif), which were mounted on a strength tester (Bisco, Inc., Schaumburg, IL, USA) and loaded in tension at a speed of $0.5 \mathrm{~mm} / \mathrm{min}$ until failure occurred at specimens. The Figure 1 showed the sequence to formation's slice to microtensile test and conversion of Newton to Mpa data.

\section{Results}

The bond strength values (in MPa) are presented in Figure 2.

The analysis of variance (ANOVA) and Tukey's post-hoc tests showed significant statistical differences $(P<.05)$ to all resin cements immediately after light-curing and 24 hours (GI and GII; GV and GVI), 48 hours and 7 days (GIII and GIV; GVII and GVIII). The Panavia $^{\circledR}$ F 2.0 showed higher mean values than RelyX ${ }^{\mathrm{TM}} \mathrm{U} 100$ for all storage times, however no different statistically significant was

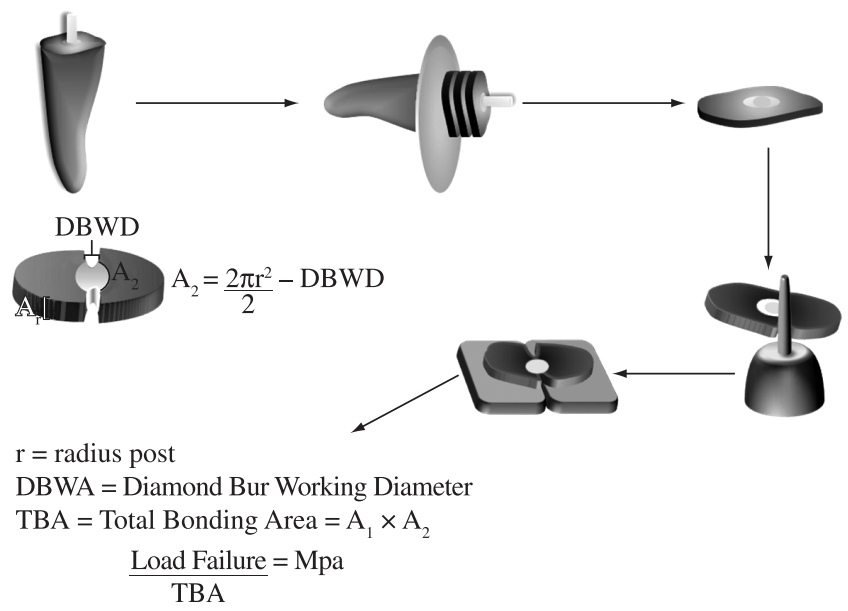

Figure 1. Schematic of formation' slices to microtensile test and conversion of Newton to Mpa data.

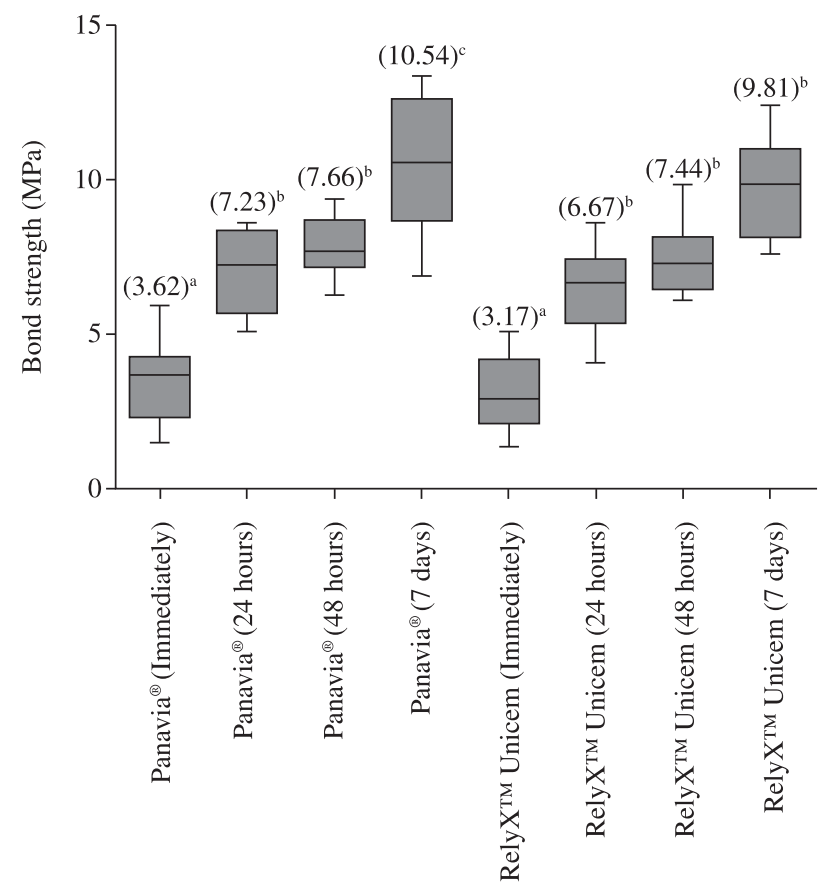

Figure 2. Bond strength values (in $\mathrm{MPa}$ ) to resin cements used in this study. Different letters $(a-c)$ indicate statistically significant difference at $5 \%$ level (Tukey's test; $\mathrm{p}<0.05$ ). reported $(P>.05)$. The resin cements 24 and 48 hours (GII and GIII; GVI and GVII) after light-curing were statistically similar among themselves $(P>.05)$.

\section{Discussion}

This in vitro study evaluated the bond strength of two commercially available dual-cure resin cements with microtensile test.

The root canals in the present study were filled with AH Plus ${ }^{\circledR}$ and gutta-percha before the post space preparation, which is more approximate clinical situation. Chieffi et al. ${ }^{21}$ (2006) showed that resin sealer had not a negative effect on the bond strength. In additional, the root canals were rinsed using tap water instead of EDTA and $\mathrm{NaOCl}$. The impact of EDTA and $\mathrm{NaOCl}$ on bond strength has been observed higher values, in which have effective in removing the smear layer in root canals. In contrast, EDTA used with a combination of $\mathrm{NaOCl}$ can easily produce erosion surfaces with complete opening of the dentin tubules ${ }^{22}$.

RelyX ${ }^{\mathrm{TM}} \mathrm{U} 100$ (Clicker ${ }^{\mathrm{TM}}$ Dispenser) or Unicem (Aplicap ${ }^{\mathrm{TM}}$ ) consists of specially designed multifunctional, phosphoric acid modified methacrylate monomers that form a highly cross-linked cement matrix during radical polymerization, whereas the phosphoric acid groups contribute to self-adhesion, the carbon double bonds cause a high reactivity of the methacrylate monomers with each other. ${ }^{23}$ Thus after setting of RelyX ${ }^{\mathrm{TM}} \mathrm{U100/Unicem}$, the cement matrix shows a high degree of cross-linking between the monomers, that was confirmed with evaluation of the degree of conversion by Bandéca et al. (2009) ${ }^{5}$.

The adhesion of resin cement to root dentin is dependent of the hybridization. The adhesives (when used) and resin cements are responsible to hybridization of root dentin. The Panavia ${ }^{\circledR}$ F 2.0 that uses the self-ecthing adhesive combined with resin cement showed higher values of bond strength than RelyX ${ }^{\mathrm{TM}} \mathrm{U} 100$. However, the data showed no difference significance between them $(P>.05)$ (Figure 2). Thus, this self-adhesive resin cement did perform as well as resin cement combined with self-ecthing adhesives with glass fiber post. One of the components of Rely $\mathrm{X}^{\mathrm{TM}} \mathrm{U} 100$ is phosphoric acid modified methacrylate monomers, which require wet surfaces for ionization and subsequent interaction with dentin and enamel. ${ }^{18-20}$ The specimens were storage in distillated water until testing, than the dentin was hydrated when the cement was filled inside root canal, consequently the results were similar, which was confirmed in some studies ${ }^{8,24,25}$.

The storage times analyzed in this study were due to incompleteness of the polymerization reaction in the processing of the resin cement, there are some unreacted monomers before 7 days, which it was evidenced by Bandéca et al. ${ }^{5}$.

The both resin cements used had similar aspect of bond strength evaluated on different storage times. The bond strength values 7 days after curing was higher than others storage times $(P<.05)$ (Figure 2$)$. The bond strength values was higher after 7 days, because a high degree of monomer to polymer conversion is evidenced after 7 days, increasing the conversion degree, according with Bandéca et al. (2009) ${ }^{5}$.

The RelyX ${ }^{\mathrm{TM}} \mathrm{U} 100$ and Panavia ${ }^{\circledR}$ F 2.0 resin cements used in this study are polymerized by self- and light-activation (dual cure). The self-activation starts with the reaction between benzoyl peroxide and tertiary amine and the initiator system of light activation is based on camphoroquinone, which absorbs energy when exposed to the visible light energy in the wavelength between 400 and $500 \mathrm{~nm}$, and combines with tertiary amine to form a state complex that breaks down into reactive free radicals. ${ }^{26}$

\section{Conclusion}

Within the limitations of the current study, it can be concluded that both resin cement showed similar bond strength into root canal 
on different storage times. The highest bond strength values of the resin cements were showed 7 days after curing.

\section{Acknowledgements}

The authors would like to thank 3M/ESPE Brazil and Kuraray for providing the resin cements used in this study. This study was financial support by CAPES - Brazil.

\section{References}

1. Abo-Hamar SE, Hiller KA, Jung H, Federlin M, Friedl KH and Schmalz G. Bond strength of a new universal self-adhesive resin luting cement to dentin and enamel. Clinical Oral Investigations. 2005; 9(3):161-167.

2. Reid LC, Kazemi RB and Meiers JC. Effect of fatigue testing on core integrity and post microleakage of teeth restored with different post systems. Journal of Endodontics. 2003; 29(2):125-131.

3. Wells JD, Pashley DH, Loushine RJ, Weller RN, Kimbrough WF and Pereira PN. Intracoronal sealing ability of two dental cements. Journal of Endodontics. 2002; 28(6):443-447.

4. Mendoza DB, Eakle WS, Kahl EA and Ho R. Root reinforcement with a resin-bonded preformed post. The Journal of prosthetic dentistry. 1997; 78(1):10-14.

5. Bandéca MC, El-Mowafy O, Saade EG, Rastelli ANS, Bagnato VS and Porto-Neto ST. Changes on degree of conversion of dual-cure luting light-cured with blue LED. Laser Physics. 2009; 19(5): 1050-1055.

6. Jacobsen PH and Rees JS. Luting agents for ceramic and polymeric inlays and onlays. International Dental Journal. 1992; 42(3):145-149.

7. Ceballos L, Garrido MA, Fuentes V and Rodriguez J. Mechanical characterization of resin cements used for luting fiber posts by nanoindentation. Dental Materials. 2007; 23(1):100-105.

8. De Munck J, Vargas M, Van Landuyt K, Hikita K, Lambrechts P and Van Meerbeek B. Bonding of an auto-adhesive luting material to enamel and dentin. Dental Materials. 2004; 20(10):963-971.

9. Abo-Hamar SE, Hiller KA, Jung H, Federlin M, Friedl KH and Schmalz G. Bond strength of a new universal self-adhesive resin luting cement to dentin and enamel. Clinical Oral Investigations. 2005; 9(3):161-167.

10. Yang B, Ludwig K, Adelung R and Kern M. Micro-tensile bond strength of three luting resins to human regional dentin. Dental Materials. 2006; 22(1):45-56.

11. Goracci C, Cury AH, Cantoro A, Papacchini F, Tay FR and Ferrari M. Microtensile bond strength and interfacial properties of self-etching and self-adhesive resin cements used to lute composite onlays under different seating forces. Journal of Adhesive Dentistry. 2006; 8(5):327-335.

12. Hikita K, Van Meerbeek B, De Munck J, Ikeda T, Van Landuyt K, Maida $\mathrm{T}$ et al. Bonding effectiveness of adhesive luting agents to enamel and dentin. Dental Materials. 2007; 23(1):71-80.
13. Chung KH and Greener EH. Correlation between degree of conversion, filler concentration and mechanical properties of posterior composite resins. Journal of Oral Rehabilitation. 2007; 17(5):487-494.

14. Mallmann A, Jacques LB, Valandro LF, Mathias P and Muench A. Microtensile bond strength of light- and self-cured adhesive systems to intraradicular dentin using a translucent fiber post. Operative Dentistry. 2005; 30(4):500-506.

15. Aksornmuang J, Foxton RM, Nakajima M and Tagami J. Microtensile bond strength of a dual-cure resin core material to glass and quartz fibre posts. Journal of Dentistry. 2004; 32(6):443-450.

16. Morris MD, Lee KW, Agee KA, Bouillaguet S and Pashley DH. Effects of sodium hypochlorite and RC-prep on bond strengths of resin cement to endodontic surfaces. Journal of Endodontics. 2001; 27(12):753-757.

17. Proença JP, Polido M, Osorio E, Erhardt MC, Aguilera FS, García-Godoy $F$ et al. Dentin regional bond strength of self-etch and total-etch adhesive system. Dental Materials. 2007; 23(12):1542-1548.

18. Omar H, El-Badrawy W, El-Mowafy O, Atta O and Saleem B. Microtensile bond strength of resin composite bonded to caries-affected dentin with three adhesives. Operative Dentistry. 2007; 32(1):24-30.

19. Goracci C, Grandini S, Bossù M, Bertelli E and Ferrari M. Laboratory assessment of the retentive potential of adhesive posts: a review. Journal of Dentistry. 2007; 35(11):827-835.

20. Minto AMP, Bandéca MC, Borges AH, Nadalin MR and Thomé LHC. Bond strength of Epiphany ${ }^{\mathrm{TM}}$ Sealer combined with different adhesive systems photo-activated with LED and QTH. Laser Physics. 2009; 19(8):1872-1876.

21. Chieffi N, Sadek F, Monticelli F, Goracci C, Grandini S, Davidson C et al. Effect of dentin adhesives used as sealers and provisional cementation on bond strength of a resin cement to dentin. American Journal of Dentistry. 2006; 19(2):91-95.

22. Hayashi M, Takahashi Y, Hirai M, Iwami Y, Imazato S and Ebisu S. Effect of endodontic irrigation on bonding of resin cement to radicular dentin. European Journal of Oral Sciences. 2005; 113(1):70-76.

23. 3M/ESPE.Technical Product Profile, RelyX ${ }^{\mathrm{TM}}$ Unicem Self-Adhesive Universal Resin Cement. Seefeld, Germany; 1998.

24. Naumann M, Preuss A and Frankenberger R. Reinforcement effect of adhesively luted fiber reinforced composite versus titanium posts. Dental Materials. 2007; 23(2):138-144.

25. Naumann M, Sterzenbach G, Franke A and Dietrich T. Randomized controlled clinical pilot trial of titanium vs. glass fiber prefabricated posts: preliminary results after up to 3 years. International Journal of Prosthodontics. 2007; 20(5):499-503.

26. Braga RR, Cesar PF and Gonzaga CC. Mechanical properties of resin cements with different activation modes. Journal of Oral Rehabilitation. $2002 ; 29(3): 257-262$. 